\title{
Mobile Money and Risk Sharing Against Village Shocks
}

May 14, 2018

\begin{abstract}
Households in developing countries have gained increased access to remittances through the recent introduction of mobile money services. I examine the impact of these mobile money services on consumption after a rainfall shock, such as a flood or drought, for both users of mobile money and for household that don't use mobile money but who reside in villages with other users. This allows me to determine the extent that remittances received via mobile money are shared within villages, creating wider benefits to the community. Using a difference-in-difference fixed effects specification, I find that after a village-level rainfall shock it is only users of mobile money who are able to prevent a drop in their consumption. There are no spillover effects to other members of the village. This finding has implications for how new technologies might change traditional risk sharing arrangements, and who might benefit and lose out from their spread.
\end{abstract}

Keywords: risk sharing, mobile money, Tanzania

JEL Classification - O16, O17, O33 


\section{Introduction}

In developing countries, households use informal risk sharing networks to smooth their consumptions in response to unanticipated idiosyncratic shocks such as illness or death. Households within a network can insure their idiosyncratic shocks through cross-sectional risk sharing which allows a household in a network who is affected by a shock to receive transfers from those who aren't affected, assuming not everyone in the same network is subject to the same shock at once. This sort of risk sharing has been found to exist both within and across villages, though it is often found to be incomplete (Townsend, 1994; Udry, 1994; De Weerdt and Dercon, 2006; Kinnan, 2017; Gertler and Gruber, 2002; Kazianga and Udry, 2006)

However, if the network is clustered in one geographical location, such as within a village, aggregate shocks to that village, such as a flood or drought, could occur, affecting all of the village at once. Larger risk sharing networks of friends and families in other villages could be used to insure this risk by sending remittances, but in practice it is costly and time consuming to send money long distances due to high transaction costs. Without a fast, cheap and secure method of sending remittances long distances, cross-village insurance networks will not be able to respond to shocks amongst their members.

Mobile money services are a new tool allowing small amounts of money to cheaply, quickly and safely be sent around the country via a mobile phone, dramatically increasing access to a wider remittance network that households can draw from. By facilitating risk sharing outside the village with people in other communities, which will be less likely to have experienced the same shock, mobile money allows households to insure themselves against aggregate shocks to their village.

This paper examines how the introduction of mobile money services allow remittances to flow into a village after a rainfall shock occurs in that village, and to what extent these remittances are shared throughout the village, allowing all households within the village to smooth their consumption. By comparing households in village with and without mobile money, and within villages with mobile money, households that do and do not use mobile money services, I can quantify the benefits of mobile money to both the recipient and to the rest of the village. While previous work has looked at the impact of mobile money on the user, no one has yet looked at the potential benefits to other members of a village when a household uses mobile money.

Likewise, previous work has not separately examined geographically clustered shocks at the village level (which I refer to here as village-level aggregate shocks) and idiosyncratic shocks. I argue a key contribution of mobile money services is enabling risk sharing when an entire village experiences a shock at once through the flow of remittances from outside to inside the village. Previous to the introduction of mobile money services, even if a household had a network outside the village, methods of sending remittances were slow and costly. This paper will build upon other 
work showing the benefit of mobile money use to the user after an idiosyncratic shock (Jack \& Suri 2014) and focus on the extent of sharing of the benefits of mobile money use within the village after a village-level rainfall shock.

I begin by looking at village-level aggregate shocks in the form of floods and drought, which are geographically concentrated, large and unexpected, and hence cannot be insured within the village. I find that household consumption is significantly negatively affected by these rainfall shocks, with household consumption falling approximately $6 \%$.

Secondly, I show that mobile money provides insurance against these rainfall shocks, resulting in household consumption of users no longer being negatively impacted by an aggregate shock to the village. The mechanism proposed here is that mobile money allows the user access to remittances from households outside the village. Mobile money therefore allows households to share risk with others outside their village, resulting in aggregate shocks to village consumption not being aggregate shocks to the household's network. When a mobile-money-user experiences a shock at the village level, they can ask for help from family and friends in other locations which have not experienced a negative shock and with whom they can reciprocally insure. Remittances can then be sent easily and cheaply via mobile money. This means users of mobile money are able to smooth their consumption after a village-based shock in a way non users aren't able to.

I confirm that remittances are the mechanism through which mobile money allows the smoothing of rainfall shocks using a cross section of remittance data from the final wave of my data. I find that mobile money users are both more likely to receive remittances and, after an aggregate shock, receive an increase in remittances of $4 \%$ of per capita income, accounting for $2 / 3$ the negative effect of the shock. While I show that remittances received via mobile money explain the majority of the fall in consumption after a rainfall shock, I cannot rule out that mobile money also helps households save and self-insure against shocks.

Thirdly, I examine the wider impact of mobile money transfers within a village, something that has not been looked at before in previous work. If insurance networks cover both users and non-users of mobile money within a village, then if a household uses mobile money and receives remittances after an aggregate shock the remittance will be shared with other non-user members of the insurance network within the village. Hence consumption of non-mobile-money users in villages with other mobile money users will also not decline as much after a village-level rainfall shock as that of households in villages without any mobile money users.

I find that while a user of mobile money is able to perfectly smooth the impact of a rainfall shock, non-users in villages with other mobile money users still experience the same fall in consumption as non-users in villages with no users. Users of mobile money are not sharing their remittances with other members of the community after a rainfall shock. A possible explanation for this is that 
recipients of mobile money are choosing not to participate in a risk sharing network with others in the village and instead are relying on networks outside the village and on the stream of remittances for insurance. Potential changes in the composition and extent of risk sharing relationships due to the introduction of mobile money are an exciting area for future research.

I examine heterogeneity in my results by distance to the nearest mobile money agent (essential for making transactions with mobile money), whether the village is in a rural or urban location and whether the rainfall shock is a flood or drought. I find suggestive evidence that droughts are the main driver of my results, and confirm this by showing droughts a have significant negative effect on crops yields, the main source of income for $2 / 3$ of these households.

I confirm the robustness of my findings using a placebo test using two periods of data from before the introduction of mobile money and an instrumental variable regression using distance to the nearest mobile money agent as an instrument for adoption. These allow me to test if mobile money use is correlated with ability to smooth risk. Neither test confirms selection, but both have large standard errors and so should be interpreted with caution.

This paper builds on the literature of the methods households in developing countries use to smooth consumption (Dercon, 2002) but shows use of these methods to be insufficient to fully smooth village-level rainfall shocks. I find that households in Tanzania without access to mobile money services suffer consumption shortfalls after aggregate shocks, here village-clustered rainfall shocks. They are unable to fully insure these shocks using other methods of smoothing consumption, such as savings or transfers from wider networks in the absence of mobile money.

However, I find that households that use mobile money are able to insure aggregate shocks, with the proposed mechanism being flows of remittances from networks of family and friends outside the village. This builds on a number of papers that have examined links to others outside the village and how households share risk across a larger network of family and friends (Fafchamps and Lund, 2003; Rosenzweig, 1988; De Weerdt and Dercon, 2006).

The mechanism proposed here through which mobile money allows risk sharing is remittances. Remittances have been shown to be an important channel through which households with family members outside the village can insure their consumption. Yang and Choi (2007) look at remittance patterns in the Philippines, finding that remittances move in opposite directions to income with $60 \%$ of the decline in income after a rainfall shock compensated for by increased remittances. Households without migrant members experience a fall in consumption. However, sending money across long distances by traditional channels such as through friends or via Western Union can be very costly, slow and unsafe, limiting the effectiveness of this channel. Mobile phone money transfer technology is able to overcome these barriers to sending remittances quickly and lower costs, allowing users access to their wider risk-sharing networks and assisting households in smoothing 
village-level shocks (Jack and Suri, 2014; Blumenstock et al., 2016; Batista and Vicente, 2014).

Jack and Suri (2014) use panel data to analyse how mobile money facilitates consumption smoothing in response to negative idiosyncratic income shocks in Kenya. They find that while the consumption of non-user households falls by 7\%-10\% after a shock, there is no corresponding fall for user households. They find that this effect is due to the improved ability to smooth risk via remittances; in the face of a negative shock, user households are $13 \%$ more likely to receive any remittances, receive more remittances and receive a larger total value amounting to 6-10\% of annual consumption. Munyegera and Matsumoto (2016) also shows that remittances are the channel through which mobile money affects consumption in Uganda, with households with mobile money 20 percentage points more likely to receive remittances, receive remittances more frequently and the total value of the remittances received are $33 \%$ higher than for non-user households. However, none of the existing literature examine spillovers in mobile money use in the form of sharing of remittances within villages, something I can shed light on. Whether mobile money services only benefit users or also have spillover benefits to others in the community is an importance factor in assessing who benefits and loses from new technologies.

The remainder of this paper is organised as follows: I first provide some context on mobile money services. I summarise the data used in this paper in section 2, outline the empirical specifications and makes predictions to be tested in the data in section 3. Section 4 covers the main results, robustness checks and mechanisms. Finally, I conclude.

\subsection{Context: Mobile money services}

Mobile money services allow users to transfer, deposit, withdraw and save money on a mobile phone. They work on basic mobile phones* using PIN secured SMS text messages and do not require the user to have a formal bank account. Mobile money services use agent networks that include airtime sellers and retail networks where customers can deposit and withdraw money. Users are charged a small fee for sending and withdrawing money using mobile money services and transaction sizes are normally capped at a few thousand US dollars. To send money to someone, only their mobile phone number is required. Services have also expanded recently to include payment of bills and taxes and to allow the combining of a mobile money account with a formal bank account. Mobile money services have spread rapidly in the developing world since the launch of th first such service, MPesa in Kenya in 2007, by "leapfrogging" traditional banking services (Aron, 2017).

Mbiti and Weil (2011) describe the impact of M-Pesa in Kenya, finding that M-Pesa changes the pattern of remittance by increasing the frequency and volume of urban-rural transfers while lowering the price of competing remittance services such as Western Union. They find $25 \%$ of

\footnotetext{
*non-smart phones
} 
people report using M-Pesa for savings, and that it lowers the probability of people using informal saving mechanisms, such as ROSCAS, while raising the probability of them being banked. Jack and Suri (2011) also look descriptively at the use of M-Pesa for sending remittances in Kenya and find that remittances sent via M-Pesa are less likely to go to parents and more likely to go to friends and other relatives than other forms of remittance. This could signal that M-Pesa users have/take advantage of a broader network than non-users. For those who don't use M-Pesa, the most commonly given reason is not owning a mobile phone followed by not needing the service. Less than $1 \%$ report not having access to an agent.

There are 4 mobile money providers in Tanzania; Vodacom's M-Pesa, Zantel's Z-Pesa and Zain's Zap (now Airtel Money), all of which launched in 2008/9, and Tigo's Tigo Pesa which launched in 2010. M-pesa is by far the largest of these with $72 \%$ of the market. Take-up of mobile money took off slowly, with only $0.5 \%$ of households having ever used mobile money in 2009 (Finscope, 2013), but after Vodacom initiated some changes at the end of 2009 the service took off, reaching a quarter of the population by the end of 2011 and a third by the end of 2013 . From only 900 agents in September 2009, the service had 17,000 by December 2013.

Mobile money requires the user to have a mobile phone and sim card from the mobile money provider. The user must register for a mobile money account and can then deposit money through that mobile money providers' agents, which are usually located in shops. The cash is then electronically deposited in the customer's account. Customers can transfer money via SMS to other people even on different networks, and make withdrawals at their network's agents anywhere in the country. Users are charged a step-tariff rate for sending money and for withdrawing money from agents, with fees for M-Pesa of around 10\% for withdrawing and 3\% for sending $\$ 5$ and falling with the amount. Depositing money on the account is free. 


\section{Data and summary statistics}

\subsection{Household panel}

The data used comes from the Tanzania National Panel survey (NPS) 2008-9, 2010-11 and 2012-13, implemented by the Tanzania National Bureau of Statistics and downloaded from the World Bank LSMS microdata catalogue. The survey covers 3,265 households in 26 districts containing 409 Enumeration Areas (EAs), and is designed to be representative of Tanzania as a whole. Within each EA (village) an average of 8 households were randomly selected. The survey made particular effort to track respondents, with all adult former households members tracked to new location, resulting in over $97 \%$ of the round 1 households being re-interviewed in round 2 and a total panel attrition rate of $4.8 \%$. The data includes weightings of the probability that an observation was included in the survey to take into account the fact that some areas were over surveyed to reflect the higher variance of the variables of interest (for example in cities).

The survey included questions on consumption, assets, finance, shocks, household characteristics and village characteristics. I combined the data by household since mobile money use is only recorded at the household level. Looking at the characteristics of the household head in table 1, the average household has 5 people, average years of education of the household head is just under 5 years, increasing slightly during the survey. $60 \%$ of household heads worked in agriculture, $10 \%$ in the private sector as paid workers and 15\% were self employed. In 2008-09 annual real per person consumption was 742,386 TZ Shillings (\$450), rising to 1,011,279 (\$568) in 2012-13.

I generated a wealth index of assets using principal component analysis (PCA) since the value of assets owned was not asked all the waves of the survey. Different components of wealth, such as the number of chickens owned or bicycle ownership, cannot easily be added up. PCA determines the relative importance of variables when seeking to summarize a set of variables. The first principal component accounts for the largest variance across the variables. In a wealth index, the first principal component is assumed to represent relative wealth. Based on this, each factor is given a factor weight representing its relative importance in constructing the principal component. I generated a wealth index score based on these factor weights.

Looking at mobile phone ownership and mobile money use, in 2008-9, 45\% of households owned at least one mobile phone, increasing to $62 \%$ in $2010-11$ and $71 \%$ in $2012-13$. $13 \%$ of households had used a mobile money service in $2010-11$ and $38 \%$ had by $2012-13$. I am interested in both users and non users in villages with mobile money and non-users in villages without mobile money. Therefore I break down the number of villages and households by these categories in Figure 1 . This figure shows the large increase in both villages with any mobile money users and the number of mobile money users and non-users within these villages. By the second round of the survey $47 \%$ of 
Table 1: HH summary stats by wave

\begin{tabular}{|c|c|c|c|c|c|c|}
\hline & \multicolumn{2}{|c|}{ Wave 1} & \multicolumn{2}{|c|}{ Wave 2} & \multicolumn{2}{|c|}{ Wave 3} \\
\hline & Mean & $\mathrm{SD}$ & Mean & $\mathrm{SD}$ & Mean & $\mathrm{SD}$ \\
\hline Per capita consumption & 743,386 & 725,334 & 862,266 & 782,264 & $1,011,279$ & $1,090,465$ \\
\hline Rainfall shock & 0.21 & 0.41 & 0.21 & 0.41 & 0.29 & 0.46 \\
\hline Mobile money use & 0.00 & 0.00 & 0.13 & 0.33 & 0.38 & 0.49 \\
\hline Rural & 0.69 & 0.48 & 0.69 & 0.46 & 0.69 & 0.46 \\
\hline Education of head (yrs) & 4.76 & 3.57 & 4.84 & 3.65 & 4.96 & 3.70 \\
\hline Female head & 0.25 & 0.43 & 0.26 & 0.43 & 0.28 & 0.446 \\
\hline Age of head & 45.53 & 15.05 & 45.85 & 15.53 & 46.71 & 16.04 \\
\hline Household size & 5.08 & 2.86 & 5.28 & 3.13 & 5.02 & 3.05 \\
\hline Own mobile & 0.45 & 0.50 & 0.62 & 0.48 & 0.71 & 0.45 \\
\hline \multicolumn{7}{|l|}{ Financial access } \\
\hline Number of loans & 0.07 & 0.30 & 0.10 & 0.35 & 0.12 & 0.39 \\
\hline Bank account & 0.0 & 0.0 & 0.20 & 0.40 & 0.20 & 0.40 \\
\hline ROSCA & 0.04 & 0.20 & 0.05 & 0.22 & 0.04 & 0.19 \\
\hline Wealthscore & -0.11 & 3.00 & 0.14 & 2.85 & -0.05 & 2.56 \\
\hline \multicolumn{7}{|l|}{ Occupational dummies } \\
\hline Agriculture/ Livestock & 0.60 & 0.49 & 0.56 & 0.50 & 0.55 & 0.50 \\
\hline Fishing & 0.02 & 0.14 & 0.01 & 0.12 & 0.01 & 0.12 \\
\hline Mining & 0.00 & 0.05 & 0.00 & 0.06 & 0.00 & 0.06 \\
\hline Tourism & 0.00 & 0.02 & 0.00 & 0.02 & 0.00 & 0.02 \\
\hline Employed: Government & 0.06 & 0.23 & 0.06 & 0.24 & 0.06 & 0.23 \\
\hline Parastatal & 0.01 & 0.08 & 0.01 & 0.08 & 0.01 & 0.07 \\
\hline Private sector & 0.09 & 0.28 & 0.11 & 0.31 & 0.12 & 0.33 \\
\hline NGO/religious & 0.01 & 0.09 & 0.01 & 0.08 & 0.01 & 0.09 \\
\hline $\begin{array}{l}\text { Self-employed (non-agri) w } \\
\text { employees }\end{array}$ & 0.02 & 0.16 & 0.03 & 0.18 & 0.03 & 0.16 \\
\hline $\begin{array}{l}\text { Self-employed (non-agri) w/o } \\
\text { employees }\end{array}$ & 0.15 & 0.35 & 0.14 & 0.35 & 0.15 & 0.36 \\
\hline Unpaid family work & 0.01 & 0.05 & 0.01 & 0.11 & 0.01 & 0.11 \\
\hline Job seeker & 0.00 & 0.05 & 0.00 & 0.07 & 0.00 & 0.04 \\
\hline
\end{tabular}




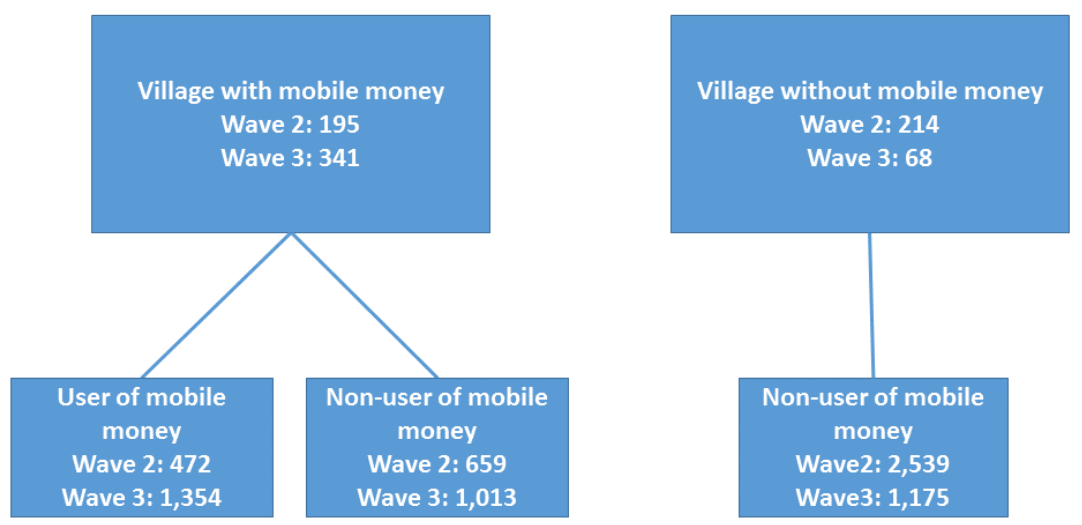

Figure 1: Break down of villages and households by mobile money use

the communities had at least one person using mobile money. By 2012-13, 83\% of the communities had at least one person using mobile money. The agent network also expanded rapidly during this period. In the second wave of the data $20 \%$ of villages had an agent in the village but this increased to $50 \%$ by the third wave.

Sending and receiving money are by far the most popular uses of mobile money, with $67 \%$ of users saying they send money and $82 \%$ of users saying they receive money. These two uses are also given as the most important use of mobile money services by $80 \%$ of respondents. $20 \%$ of people report using mobile money services to save up for emergencies and $12 \%$ have used it to pay for a good or service. $40 \%$ of people use the service at least monthly. The most common reason for not using mobile money was no mobile phone, given by just over $60 \%$ of respondents. Lack of proximity to an agent was only given as the reason for not using mobile money by $8 \%$ of respondents, also equal to those citing they don't understand the service.

In the third round of the survey there was detailed data on who sent the remittances to whom using what channel, where from and what their relationship was to the sender. $40 \%$ of remittances were sent physically via friends and family and $35 \%$ by mobile money. Only $2 \%$ was sent using a bank account, $1 \%$ using Weston Union and $0.4 \%$ using the Post Office. In the past it's probable that the majority of remittances were sent via friends and family with very little sent using any more formal channels. $40 \%$ of remittances were sent by a son or daughter with only $3.5 \%$ sent via a spouse, $7 \%$ by a parent and $17 \%$ by a sibling. $30 \%$ of remittances are sent from Dar Es Salaam and less than $3 \%$ are from abroad. This is consistent with a pattern of a family member migrating to another location such as the city within Tanzania and then sending remittances back to their family. 


\subsection{Rainfall measure}

The panel data contains information on self reported shocks, including whether a household has experienced a drought or flood. This is a dummy equal to one if the household reported that they experienced a drought or flood in the year proceeding the survey wave. To the extent that households misreport or subjectively interpret a rainfall shock, for example saying they experienced a rainfall shock to justify a poor crop yield or exaggerating the importance of a rainfall shock in a year when they have no other shocks, this measure of rainfall shocks will be subject to bias and measurement error. I therefore also calculate a rainfall shock measure per village using data from the NOAA's climate prediction centre FEWS (Famine Early Warning System). This is available at 0.1 degree resolution by latitude and longitude across Africa and was included in the Tanzania NPS summarized at the EA level.

I define a rainfall shock as more than a 1 standard deviation in absolute values from the 15 year mean by the nearest rainfall station to the village, as used in Jensen (2000). Deviations from the historic mean capture the extent that rainfall is different from what is expected, and 1 standard deviation is a large difference from normal (on average $200 \mathrm{~mm}$ difference from an average annual rainfall of $800 \mathrm{~mm}$ across the entire country). The absolute value is used because either too much or two little rainfall can be harmful. Only deviations greater than 1 standard deviation in absolute value are examined since a little bit too much or too little rain is unlikely to have a big effect, and initially more rain can have a positive effect on crop yields (Suri, 2003; Paxson, 1992). I am only interested in extreme, abnormal, rainfall deviations which could be classified as a drought or flood. The rainfall deviations in millimetres by year are shown in figures $2 \mathrm{a}$ to $2 \mathrm{~d}$.

The mechanism through which rainfall shocks negatively affect income can be varied as I look at both rural and urban households. In rural households, droughts and floods will destroy crops leading to loss of income. In urban areas, flooding is likely to be the main mechanism though which rainfall shocks affect income by preventing people from working and by destroying property. For example, in Dar es Salaam in December 2011 there were severe floods resulting in over 6,000 people being displaced and left homeless. I examine the size of these different mechanisms by examining separately droughts and floods for both urban and rural households and by examining the impact of the shock on crop yields for agricultural households. In both these examples remittances can be sent to alleviate the loss of consumption, from urban to rural households after crop losses and from rural to urban households in the case of severe floods. 
Figure 2: Deviations from mean rainfall, mm

(a) July 2009-10

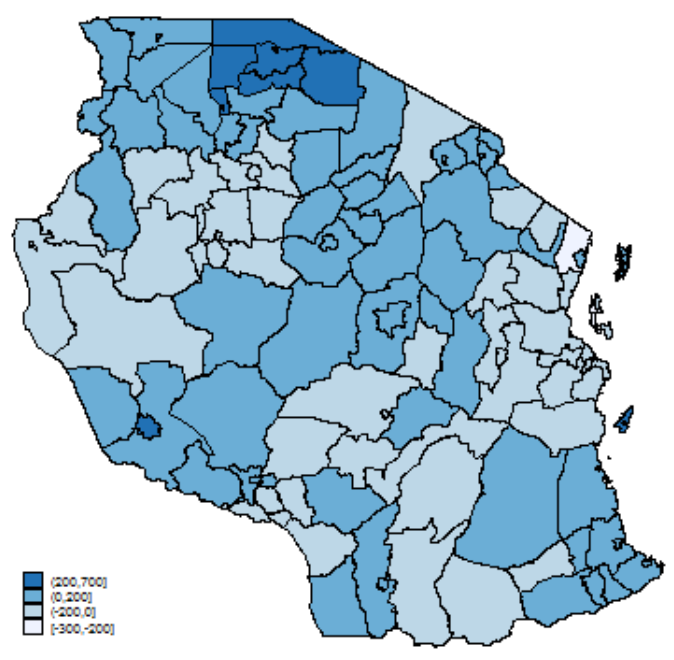

(c) July 2011-12

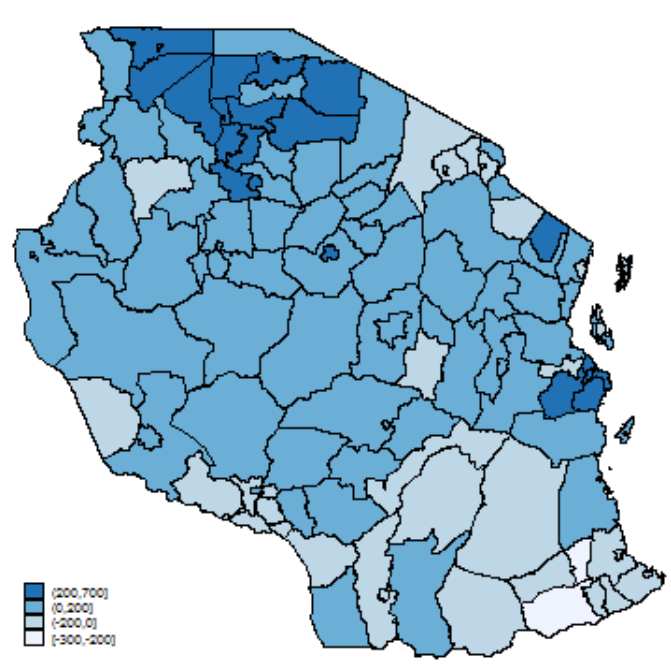

(b) July 2010-11

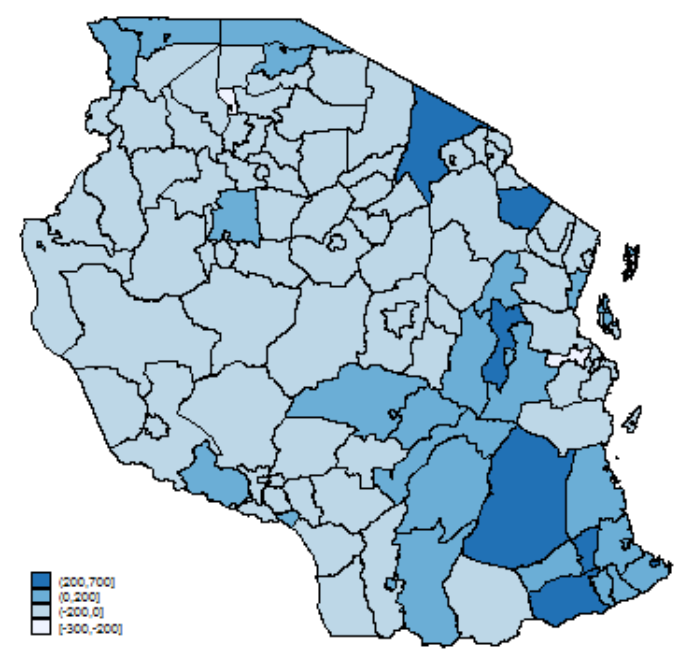

(d) July 2012-13

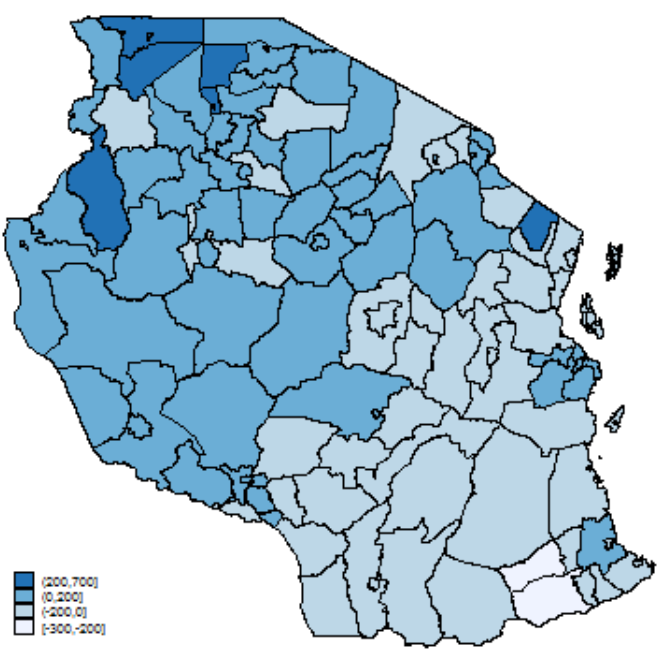




\section{Empirical framework}

\subsection{Empirical Specification}

I empirically test the impact of village-level rainfall shocks for households and villages with and without mobile money. If rainfall shocks are unable to be fully insured, they will lead to a drop in consumption. If mobile money allows for transfers to be made in response to an village-level rainfall shock, then consumption will no longer respond to aggregate shocks. If these transfers are shared with others in the village then there will be a positive spillover to non-users from other members of the community using mobile money. If transfers are kept by the user of mobile money then only the user will be able to smooth consumption after an aggregate shock.

I follow the literature ${ }^{\dagger}$ by writing an empirical specification of the impact of an aggregate rainfall shock on consumption for household with and without mobile money services:

$$
\begin{aligned}
C_{j v t}= & \gamma_{a} \text { Shock }_{j v t}+\mu M M_{j v t}+\lambda M M S p_{j v t} \\
& +\beta_{m} M M_{j v t} \cdot S_{h o c k_{j v t}}+\beta_{s p} M M S p_{j v t} \cdot \text { Shock }_{j v t} \\
& +\boldsymbol{\theta} \boldsymbol{X}_{\boldsymbol{j v t}}+\boldsymbol{\psi} \boldsymbol{X}_{\boldsymbol{j v t}} \cdot \text { Shock }_{j v t}+\alpha_{j}+\delta_{t}+\varepsilon_{j v t}
\end{aligned}
$$

where $C_{j v t}$ is household $j$ 's per capita log consumption in village $v, S h o c k_{j v t}$ is a rainfall shock in village $v, M M_{j v t}$ is mobile money use by household $j$ in village $v, M M S p_{j v t}$ is an indicator if household $\mathrm{j}$ doesn't use mobile money themselves but resides in a village $v$ with at least one other mobile money user (a mobile money spillover household), $\boldsymbol{X}_{\boldsymbol{j} \boldsymbol{v} \boldsymbol{t}}$ is a vector of controls consisting of household demographics, financial service use and occupation dummies to control for any other variables which might enable households to better smooth consumption, $\alpha_{j}$ is a household fixed effect, $\delta_{t}$ is a time trend and $\varepsilon_{j v t}$ is a time varying error.

The parameters of interest are $\beta_{m}$, which allows for use of mobile money to affect the household's ability to smooth shocks and $\beta_{s p}$, which allows for being a mobile money spillover household to impact the household's ability to smooth shocks.

This gives the following predictions for the empirical estimation:

Prediction 1 For households in villages without mobile money (when $M M_{j v t}=0$ and $M M S p_{v t}=0$ ), $\gamma_{a}<0$ so that rainfall shocks have negative effects on consumption

Prediction 2 If users of mobile money receive remittances after an aggregate shock then $\beta_{m}>0$.

Prediction 3 For households in villages with other mobile money user that don't use mobile money themselves, if there is some sharing of remittances within the village after an aggregate shock then $\beta_{s p}>0$.

\footnotetext{
${ }^{\dagger}$ This is the specification form used by Jack and Suri (2014) which also follows Gertler and Gruber (2002)
} 


\subsection{Identification strategy}

I estimate (1) using a household fixed effects difference-in-difference specification. In the fixed effects case, difference-in-difference subtracts the average change in the control group (households in villages without mobile money) from the average change in the treatment group (users of mobile money or non-users in villages with mobile money), therefore removing biases from permanent differences between the two groups (captured in the fixed effects $\alpha_{j}$ ) and changes due to a time trend $\left(\delta_{t}\right)$.

There are two main self-selection effects with regards to mobile money which could bias my results. The first is self-selection by households into using mobile money. If household selection into mobile money use is correlated with unobservables that affect their ability to deal with shocks that will bias my results, creating a spurious positive association between mobile money use and shock smoothing. Secondly there may be selection by mobile money agents into which villages they choose to locate in. Again, if this selection into villages is correlated with unobserved household ability to smooth shocks this will bias my results, again creating a spurious positive association between mobile money use and shock smoothing.

Starting with self-selection by a household into using mobile money: Self-selection effects into using mobile money are absorbed into the coefficient $\mu$ on $M M_{j v t}$, which is not the focus of my analysis, as I am only interested in the effects of using mobile money after an exogenous aggregate shock. Self-selection into using mobile money is very likely, and in Table 2 column (1) I show that a variety of different observable characteristics predict mobile money adoption ${ }^{\ddagger}$. Despite adoption of mobile money not being the focus of my analysis, I still control for these observable characteristics which are correlated with mobile money use in all the regressions. Any unobservable fixed characteristics that may be correlated with mobile money use are controlled for using household fixed effects.

My analysis is focused on the ability of mobile money to help insure rainfall shocks. I am therefore concerned about selection into mobile money use being positively correlated with a household's ability to smooth shocks $\left(M M_{j v t} \cdot S h o c k_{j v t}\right.$ being positively correlated with the error term $\epsilon_{j v t}$ conditional on the household fixed effects and other covariates). Likewise, for equation (1) to identify the impact of being a spillover household, $S h o c k_{j v t} \cdot M M S p_{v t}$ must be uncorrelated with the error term conditional on the household fixed effects and other covariates.

For this identifying assumption to be satisfied, the rainfall shock must be exogenous. I confirm this by running separate fixed effect regressions for different household characteristics for each of the rainfall shocks, the results of which are shown in Table 2 columns (3) and (4). For the self

\footnotetext{
† the table shows that being wealthier, having an older and better educated household head, owning a mobile phone and a bank account all increase the probability of a household using mobile money.
} 
Table 2: Correlations of mobile money and rainfall shocks

\begin{tabular}{|c|c|c|c|c|}
\hline & \multicolumn{2}{|c|}{ Mobile money } & \multicolumn{2}{|c|}{ Rainfall } \\
\hline & $\begin{array}{l}\text { Use } \\
(1)\end{array}$ & $\begin{array}{c}\text { Agent point } \\
\text { (2) }\end{array}$ & $\begin{array}{c}\text { Self-reported } \\
(3)\end{array}$ & $\begin{array}{c}1 \mathrm{sd} \\
(4)\end{array}$ \\
\hline \multirow[t]{2}{*}{ MM agent point } & 0.285 & & -0.045 & 0.056 \\
\hline & $(0.028) * * *$ & & $(0.031)$ & $(0.052)$ \\
\hline \multirow[t]{2}{*}{1 sd rainfall shock } & -0.007 & -0.011 & 0.102 & \\
\hline & $(0.029)$ & $(0.067)$ & $(0.023)^{* * *}$ & \\
\hline \multirow[t]{2}{*}{ Self-reported rainfall shock } & 0.112 & -0.039 & & \\
\hline & $(0.045)^{*}$ & $(0.212)$ & & \\
\hline \multirow[t]{2}{*}{ Log per capita consumption } & 0.000 & 0.000 & 0.000 & -0.001 \\
\hline & $(0.000)$ & $(0.000)$ & $(0.024)$ & $(0.006)$ \\
\hline \multirow[t]{2}{*}{ Wealth } & 0.019 & -0.007 & 0.027 & 0.025 \\
\hline & $(0.005)^{* * *}$ & $(0.027)$ & $(0.011)^{*}$ & $(0.024)$ \\
\hline \multirow[t]{2}{*}{ Head education } & 0.000 & -0.027 & 0.005 & 0.01 \\
\hline & $(0.006)$ & $(0.024)$ & $(0.009)$ & $(0.023)$ \\
\hline \multirow[t]{2}{*}{ Head age } & 0.001 & 0.000 & 0.002 & -0.005 \\
\hline & $(0.000)^{* * *}$ & $(0.000)$ & $(0.001)^{*}$ & $(0.005)$ \\
\hline \multirow[t]{2}{*}{ Household size } & 0.027 & 0.023 & 0.022 & 0.026 \\
\hline & $(0.003)^{* * *}$ & $(0.009)^{*}$ & $(0.004)^{* * *}$ & $(0.012)^{*}$ \\
\hline \multirow[t]{2}{*}{ Mobile phone } & 0.175 & 0.219 & 0.048 & 0.077 \\
\hline & $(0.004)^{* * *}$ & $(0.018)^{* * *}$ & $(0.03)$ & $(0.126)$ \\
\hline \multirow[t]{2}{*}{ Number of loans } & 0.056 & 0.259 & 0.017 & -0.164 \\
\hline & $(0.027)^{*}$ & $(0.18)$ & $(0.031)$ & $(0.161)$ \\
\hline \multirow[t]{2}{*}{ Bank account } & 0.413 & 1.115 & 0.134 & 0.103 \\
\hline & $(0.029)^{* * *}$ & $(0.164)^{* * *}$ & $(0.050)^{* *}$ & $(0.125)$ \\
\hline \multirow[t]{2}{*}{ ROSCA } & 0.108 & 0.37 & 0.086 & -1.071 \\
\hline & $(0.047)^{*}$ & $(0.344)$ & $(0.065)$ & $(0.308) * * *$ \\
\hline \multicolumn{5}{|l|}{ Occupation dummies } \\
\hline \multirow[t]{2}{*}{ Agriculture } & -0.005 & -0.291 & 0.067 & -0.041 \\
\hline & $(0.047)$ & $(0.222)$ & $(0.035)$ & $(0.197)$ \\
\hline \multirow[t]{2}{*}{ Fishing } & -0.069 & 0.329 & 0.038 & -0.155 \\
\hline & $(0.159)$ & $(0.685)$ & $(0.128)$ & $(0.45)$ \\
\hline \multirow[t]{2}{*}{ Public sector } & 0.179 & 0.042 & -0.056 & 0.328 \\
\hline & $(0.073)^{*}$ & $(0.444)$ & $(0.111)$ & $(0.326)$ \\
\hline \multirow[t]{2}{*}{ Private sector } & -0.012 & 0.000 & 0.021 & 0.087 \\
\hline & $(0.042)$ & $(0.225)$ & $(0.07)$ & $(0.193)$ \\
\hline \multirow[t]{2}{*}{ Self employed } & 0.006 & -0.123 & -0.086 & 0.014 \\
\hline & $(0.039)$ & $(0.211)$ & $(0.054)$ & $(0.172)$ \\
\hline $\mathrm{F}$ test $\mathrm{p}$ value & 0.002 & 0.147 & 0.071 & 0.249 \\
\hline Obs & 9281 & 1228 & 9281 & 1228 \\
\hline
\end{tabular}

Average marginal effects from fixed effects logit regressions. Each row is a separate regression. Columns (1) and (3) are at the household level and errors are clustered at the village level. Columns (2) and (4) are at the village level Village clustered standard errors in brackets, ${ }^{* * *} \mathrm{p}<0.01,{ }^{* *} \mathrm{p}<0.05,{ }^{*} \mathrm{p}<0.1$ 
reported rainfall shocks in column (3), households that experience a 1 standard deviation rainfall shock are more likely to report experiencing a shock. Larger households and households with bank accounts are also more likely to report a shock. The F test of the joint significance of all the variables in Table 2 shows that they are jointly significant at the $10 \%$ level, suggesting the self-reported shock may be a biased measure.

In column (4), the 1 standard deviation rainfall shock, places with larger households and less ROSCA membership are correlated with more rainfall shocks, though this is no more than would be expected by chance. Jointly all the coefficients are insignificant. This suggest my 1 standard deviation rainfall shock is not correlated with characteristics of the households, confirming its use as an exogenous aggregate shock.

Since I have shown the rainfall shock to be exogenous, I am only concerned with factors which cause a household to use mobile money or reside in a village with other users also helping them smooth consumption following a shock. Bias such as this would inflate the size of the coefficients on these interaction terms and create the false conclusion that mobile money facilitates risk sharing rather than something else correlated with its uptake facilitating risk sharing. To control for observed factors which could be both correlated with mobile money use and help a household smooth consumption after an aggregate shock, I include the interaction of household characteristics with the rainfall shock in some of the specifications $\left(\boldsymbol{\psi} \boldsymbol{X}_{\boldsymbol{j} v \boldsymbol{t}} \cdot\right.$ Shock $\left._{j v t}\right)$.

To examine whether unobserved factors that influence mobile money update also affect shock smoothing, I use a placebo specification to test for common trends in previous shock smoothing before the introduction of mobile money, and an instrumental variable regression to instrument for mobile money use with something that can only influence consumption smoothing through the decision to use mobile money services.

The use of a difference-in-difference specification requires the common trends assumption. Common trends assumes that there are no differences in the consumption changes of users and non-users, had the users not actually used mobile money i.e. there are no time varying variables that differentially affect the mobile money using and non-using households consumption smoothing except adoption of mobile money. A example of such a violation of common trends is a time varying unobservable such as risk preferences which is correlated with both mobile money adoption and consumption smoothing ability. Such an unobservable would bias upwards my results. Under common trends, the counterfactual levels for the two groups can be different but the time trends must be the same so that in the absence of the use of mobile money the change in per capita consumption would have been the same for the two groups. I test this assumption by running a placebo test (see Robustness section), examining if people who went on to adopt mobile money were already better able to smooth consumption in the past. 
Secondly I test for endogeneity in mobile money use and consumption smoothing after a shock using an instrumental variables regression (see the Robustness Section). I use distance to the nearest mobile money agent as a variable which should be both correlated with mobile money use and uncorrelated with households' risk sharing ability. This relies on the assumption that mobile money agent location choice is also not correlated with consumption smoothing ability, bringing me onto the second potential source of bias.

The second potential source of bias is if there is self-selection by mobile money agents into villages. If mobile money agents are more likely to select into villages with certain citizen characteristics, such as wealthier inhabitants, whose income is also less sensitive to shocks, this could confound my results creating a spurious positive effect of mobile money. The roll-out of the agent network can shed some light on this. The majority of mobile money agents, especially early on in the launch of mobile money services, were existing sellers of airtime and sim cards. These small businesses already had links with the mobile operators and were spread throughout the country where mobile phone ownership was an already high $45 \%$ and cellular coverage was $75 \%$ of the population (Shkaratan, 2010).

Vodacom, the first and by far the largest mobile money operator in Tanzania, used aggregators to sign-up their existing airtime sellers as agents extremely quickly rather than dealing directly with thousands of outlets spread across the country (GSMA, 2010; International financial Coporation, 2010; USAID, 2013). This also allowed Vodacome to launch its mobile money services simultaneously nationwide instead of a regional roll-out. These aggregators provide liquidity to agents, allowing agents to be located in areas without bank access, and provide their initial training. Agents take a commission on the transactions and pay no fixed costs for being an agent, meaning that agents do not need a minimum number of mobile money users in their area to make the business viable. Since most agents operate out of an existing business selling airtime there is little movement of agents to, for example, wealthier locations, though there is a higher density of agents in wealthier and more populated locations such as cities.

According to the Finscope (2013), in 2013 74\% of households were within 1 hour of a mobile money agent, varying between $94 \%$ in urban areas and $64 \%$ in rural areas. This shows just how quickly the mobile money network was set up and how good the coverage is, especially compared to an alternative financial services such as Microfinance institution, which only $22 \%$ of the population were within 1 hours journey of in 2013. In the survey data used here only $8 \%$ of respondents reported lack of access to an agent as their reason for not using mobile money.

To examine whether mobile money agent presence is correlated with village characteristics, I run a logistic regression of the presence of a mobile money agent within the village on average observed characteristics of the village inhabitants and the rainfall shock indicators (with each covariate a 
separate regression) and village fixed effects to control for non-time varying characteristics of the village. Since the presence of a mobile money agent is determined at the village level, the level of observation is the village rather than the household and variables are village level means. In Table 2 column (2), I show the average marginal effect of each covariate.

Of these, mobile phone ownership and bank account ownership are significant at the $1 \%$ level, suggesting agents are locating in villages which show a tendency to adopt technology. Since mobile money use requires a mobile phone, it would be surprising if agent presence in a village was not correlated with mobile phone ownership. However the full set of covariates are jointly insignificant at the $15 \%$ level and other factors potentially correlated with the ability to smooth shocks such as wealth, credit access (loans) and education are not significant. Importantly, the rain shock is insignificant suggesting agents are not locating in areas which experience more or less shocks.

These correlations give an indication of whether contemporaneous characteristics of the village are correlated with agent presence but says nothing about the direction of the relationship or causation. It could equally be that mobile phone ownership increases if there is an agent in the village! I therefore also examine in the Robustness section whether the introduction of an agent in a village was predicted by the change of average household characteristics and village services the previous year. This provides causal evidence using the time series nature of my data to see whether agents are responding to changing household and village characteristics.

As a final note, my analysis focuses on the impact of shocks which affect an entire village at once, since these are the types of shock for which mobile money accounts allow consumption smoothing, when previously this was difficult and costly. I therefore also confirm that the rainfall shocks are affecting most people in the village at once. To do this I look at the intra-class correlation, which measures the proportion of overall variance explained by within group variance. An intra-class correlation of 1 means the variable is the same for everyone in the class, here enumeration areas.

The intra-class correlation for the one standard deviation rainfall shock is 0.849 which is not surprising given rainfall was defined for an enumeration area. The fact that it is not one likely results from the clustering of city based enumeration areas together. The self-reported rainfall shock has an intra-class correlation of 0.13 , showing some correlation within a village of households reporting a rainfall shock. The fact this is not higher could be because rainfall shocks have different effects on households depending on their household and plot characteristics, resulting in a house reporting a flood or drought when others in the village don't or vice versa. This also suggests the self-reported rainfall shock is less good as a measure of village shocks, and so my main results will be based on the 1 standard deviation rainfall shock definition, with the self-reported shock included for comparability with other research . $^{2}$

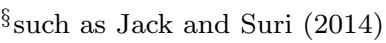




\section{Results}

This section begins by examining the impact of aggregate shocks on users of mobile money, nonusers and non-users within villages with other mobile money users. I then look at heterogeneous effects by distance to the nearest agent, urban and rural households and droughts and floods. I finish by looking at remittances as the proposed mechanism through which mobile money allows shocks to be insured and examine crop yields as one mechanism through which the rainfall shock negatively affects consumption.

\subsection{Main result}

Table 3 shows the primary results of this paper: regression results of the impact of aggregate shocks on consumption for mobile money users and non-users in villages with and without other mobile money user, as in equation (1). All regressions include the full sets of household covariates from Table 1. All regressions also control for village characteristics which could affect the ease of sending remittances. These are the distance to the nearest main road, distance to nearest population centre and distance to nearest market. The data is also weighted in all regressions by the inverse of the probability that the observation is included in the survey. Standard errors are clustered at the village level since mobile money agents are located by village and so the decision to use mobile money will be correlated within villages but not across villages.

The first two columns of Table 3 show results using self reported droughts or floods, whereas the final two columns show results using the measure of a rainfall shock as a greater or less than 1 standard deviation difference from the mean. Mobile money (MM) use refers to households than use mobile money themselves. MM spillover refers to a household residing in a village with mobile money users but who doesn't use mobile money itself.

Columns (1) and (3) are difference-in-difference regressions with household fixed effect and columns (2) and (4) also include interaction terms of all the control variables with the rainfall shock. The interaction term with the shock variable, $\boldsymbol{X}_{j v t} \cdot S h o c k_{j v t}$, controls for any changes in observable household characteristics which might impact the household's ability to smooth shocks. It can be seen from Table 1 that many of the demographic variables changed over time including education, mobile phone ownership and loans which all increased across the three waves. These could help a household smooth shocks, for example by mobile phone ownership providing access to information about shocks which makes it easier for households to smooth shocks. Including a set of covariates and interactions of these covariates with the shock controls for any effects of these variables on consumption smoothing.

Beginning with columns (1) and (3) (no shock interactions), the total effect of the rainfall shock 
Table 3: Impact of rainfall shocks on consumption for mobile money users and non-users Dependent variable: Log consumption per capita

\begin{tabular}{|c|c|c|c|c|}
\hline & \multicolumn{2}{|c|}{ Self-reported shock } & \multicolumn{2}{|c|}{1 sd rainfall shock } \\
\hline & $(1)$ & $(2)$ & $(3)$ & $(4)$ \\
\hline \multirow[t]{2}{*}{ Rain shock } & $-0.064^{* *}$ & -0.205 & $-0.068 * * *$ & -0.040 \\
\hline & $(0.029)$ & $(0.164)$ & $(0.020)$ & $(0.144)$ \\
\hline \multirow[t]{2}{*}{ Shock*MM use } & $0.088^{*}$ & 0.042 & $0.121^{* * *}$ & $0.139 * * *$ \\
\hline & $(0.051)$ & $(0.058)$ & $(0.041)$ & $(0.045)$ \\
\hline \multirow[t]{2}{*}{ Mobile money use } & 0.005 & 0.005 & -0.003 & -0.007 \\
\hline & $(0.026)$ & $(0.026)$ & $(0.026)$ & $(0.027)$ \\
\hline \multirow[t]{2}{*}{ Shock*MM spillover } & -0.057 & -0.072 & 0.005 & -0.012 \\
\hline & $(0.049)$ & $(0.052)$ & $(0.040)$ & $(0.040)$ \\
\hline \multirow[t]{2}{*}{ Mobile money spillover } & 0.002 & 0.003 & 0.005 & -0.012 \\
\hline & $(0.027)$ & $(0.027)$ & $(0.025)$ & $(0.025)$ \\
\hline Observations & 9,281 & 9,281 & 9,281 & 9,281 \\
\hline Number of households & 3,807 & 3,807 & 3,807 & 3,807 \\
\hline R-squared & 0.194 & 0.198 & 0.196 & 0.202 \\
\hline Interactions with shock & & YES & & YES \\
\hline \multirow[t]{2}{*}{ Negative shock } & $-0.057^{* *}$ & $-0.068^{* * *}$ & $-0.045^{* * *}$ & -0.024 \\
\hline & $(0.022)$ & $(0.026)$ & $(0.015)$ & $(0.017)$ \\
\hline \multirow[t]{2}{*}{ (A) Shock MM user } & 0.024 & 0.007 & 0.053 & $0.059^{*}$ \\
\hline & $(0.044)$ & $(0.045)$ & $(0.036)$ & $(0.033)$ \\
\hline \multirow[t]{2}{*}{ (B) Shock Spillover } & $-0.121^{* * *}$ & $-0.126^{* * *}$ & $-0.063^{*}$ & -0.043 \\
\hline & $(0.041)$ & $(0.040)$ & $(0.033)$ & $(0.034)$ \\
\hline \multirow[t]{2}{*}{ (C) Shock Non MM village } & $-0.064^{* *}$ & $-0.074^{* *}$ & $-0.068^{* * *}$ & $-0.042^{*}$ \\
\hline & $(0.029)$ & $(0.032)$ & $(0.020)$ & $(0.022)$ \\
\hline \multirow[t]{2}{*}{ (D) Shock Spillover $\mid u s e r X^{\prime} s$} & & $-0.107^{* *}$ & & $-0.092 * * *$ \\
\hline & & $(0.032)$ & & $(0.048)$ \\
\hline \multirow[t]{2}{*}{ (E) Shock Non MM village $\mid$ user $X^{\prime} s$} & & -0.035 & & $-0.081 * * *$ \\
\hline & & $(0.053)$ & & $(0.029)$ \\
\hline $\mathrm{F}$ stat $(\mathrm{A})=(\mathrm{C})$ & $3.00^{*}$ & $2.71^{*}$ & $8.80^{* * *}$ & $6.31^{* * *}$ \\
\hline $\mathrm{F}$ stat $(\mathrm{A})=(\mathrm{B})$ & $6.31^{* *}$ & $5.88^{* *}$ & $5.55^{* *}$ & $4.63^{* * *}$ \\
\hline F stat $(B)=(C)$ & 1.37 & 1.14 & 0.01 & 0.00 \\
\hline$F$ stat $(A)=(D)$ & & $3.95^{* *}$ & & $9.36^{* * *}$ \\
\hline$F$ stat $(A)=(E)$ & & 0.53 & & $9.77^{* * *}$ \\
\hline
\end{tabular}

Regressions include full set of household control variables from Table 1, errors clustered at the village level and control for village characteristics which could affect the ease of sending remittances (distance to the nearest main road, distance to nearest population centre and distance to nearest market). When there are interactions with the shock this set of control variables is interacted with the shock but not shown here for brevity. Mobile money use is a dummy variable equal to one if that household uses mobile money. Mobile money spillover refers to a household in a village where others use mobile money but who doesn't use themselves.

Village clustered standard errors in brackets, ${ }^{* * *} \mathrm{p}<0.01,{ }^{*} * \mathrm{p}<0.05,{ }^{*} \mathrm{p}<0.1$ 
is given below the coefficients and shows the average effect of the shock for the entire sample. The total effect of the rainfall shock for mobile money using households, spillover households and households in villages without mobile money are reported underneath the regression results for easy comparability across regression specifications (rows (A) to (C)).

When there are shock interactions (columns (2) and (4)), each control variable is interacted with the rainfall shock and included in the regression, though the coefficients are not reported here for brevity. To get the total effect of the rainfall shock overall and for each household type, I take the mean value of each control variable for that household type and multiply it by the coefficient on the interaction term $\%$. These are summed to give the total effect of the rainfall shock for households with the mean characteristics of the entire sample, mobile money users, spillover household and non-spillover households respectively. I also show the overall effect of the shock for spillover households and households in villages without mobile money using the mean values of the control variables for households that use mobile money (rows (D) and (E)). This method accounts for how other differences in characteristics of mobile-money-using and spillover households might facilitate smoothing of the rainfall shock compared to non-users.

Looking at the regression results, the rainfall shock causes a drop in consumption of approximately $6 \%$ and is significant at at least the $10 \%$ level for households in villages without mobile money (line C) in all specifications. Hence large rainfall shocks have a strongly negative effect on consumption per capita, confirming prediction 1 that in the absence of any mobile money use by the household or village, rainfall shocks have a negative effect on consumption.

Turning to the interactions with the shock dummy; the household mobile money use interaction with the aggregate shock is $9 \%-14 \%$ and significant in three out of four regressions. When a rainfall shock occurs the household using mobile money no longer experiences a drop in consumption and may even get a slight increase in consumption, as seen from the coefficients at the bottom of the table in row A being positive in all cases for both shock definitions. The F-test in the panel below comparing $\mathrm{A}$ to $\mathrm{B}$ and $\mathrm{C}$ confirms in all cases that the shock impact for mobile money users is significantly different from non-users, both in their own village and other villages. Additionally, in 3 out of 4 cases when the effect of the shock is evaluated for the spillover and non-spillover households using the mean values of the control variables for mobile-money-using households (comparing (A)

\footnotetext{
ๆFor example, for household that use mobile money the average household size is 4.9, for spillover households its 4.8 and for non-spillover household 5.2. This mean value of the variable is multiplied by the coefficient on the shock interaction with household size for each type of household. This is repeated for all the interactions terms with the rainfall shock and these are added together to give the total effect of the rainfall shock for a household with the average set of control variables for mobile money users, spillover households and non-spillover households and for spillover and non-spillover households if they had the same mean value of the control variables as mobile money using households.
} 
to (D) and (E)) I can still reject the equality of the shocks. This confirms prediction 2; mobile money users are able to smooth consumption when a rainfall shock occurs.

In contrast, when a rainfall shock occurs, being a spillover household has a negative or zero and insignificant effect on ability to smooth a shock. Row B below the main results shows that spillover households experience a large fall in consumption of as much as $12.6 \%$ after a rainfall shock. However, the F-statistics comparing row B to $\mathrm{C}$ show that I cannot reject that the impact of the shock is the same (negative impact) as that of households in a village without mobile money. Hence households do not benefit from having other people using mobile money in the village when a rainfall shock occurs. This invalidates predicted 3 .

The coefficient on mobile money use is small and insignificant in all the regressions. Therefore there is no increase in consumption for a household simply from using mobile money services, which could have been the case if for example using mobile money services allowed a new form of payments for a business or when selling agricultural goods, increasing sales and incomes. This is an interesting result of itself and conflicts with Munyegera and Matsumoto (2016) but agrees with Batista and Vicente (2014) who find no impact of mobile money services on consumption. The coefficient on being a spillover household is not significant and is very small and precisely estimated. It therefore seems that non-mobile money users do not gain from having mobile money users residing in the same village as them.

Overall this suggests that when a negative shock for the village occurs, users keep any increase in remittances for themselves and do not give any detectable amount to the rest of the village to help others smooth the shock. There are many potential explanations for this result, such as changing risk sharing networks within the village or hidden income. For example, if mobile money users are choosing to insure themselves with a migrant in another location, due to a lower covariance of shocks, they may no longer participate in risk sharing within the village. I explore these in detail in the Discussion section, but understanding how mobile money services are affecting traditional risk sharing relationships is vital to understand if there are winners and losers from this new technology.

A comparison of the self-reported shock definition and actual rainfall shock definition shows that both result in an approximate $6 \%$ fall in consumption (row $\mathrm{C}$ ). The coefficient on the shock interaction with mobile money use is smaller though, and only significant in one of the specifications. Since the self-reported shock is not highly covariate at the village level (the intra-cluster correlation is only 0.13 ) this could be due to it reflecting a shock that does not have a sufficient aggregate village-level impact and that can be partially smoothed within the village. This is in contrast to the 1 sd rainfall shock which impacts consumption of the entire village at once. This suggests that the 1 sd rainfall shock is a superior shock to use as an village-level shock and so only 
this rainfall shock definition will be used from here onwards where possible. Since the coefficients are very similar between specifications (3) and (4), only specification (3) will be used when reporting further results, though all regressions have also been run using specification (4) without any differences in results.

\subsubsection{Heterogeneous effects}

I examine a number of different effects to understand which factors might be driving the main result. These are reported in Table 4. I examine whether the results depend on the distance to the nearest mobile money agent, whether the effects differ by rural and urban households and lastly whether there are differential effects of rainfall shocks defined as a drought or flood $(<$ or $>1 \mathrm{sd})$. For all these regressions I only consider the 1 standard deviation rainfall shock measure.

The distance to the nearest mobile money agent could impact how easy it is for someone to send and receive remittances via mobile money and hence the benefit they receive from using this service. I therefore run specification (1) with interactions with dummy variables for whether an agent is within $1 \mathrm{~km}$ of the villagell. This will also indicate whether the distance to the nearest mobile money agent changes the pattern of sharing remittances within the village. For example, it might be easier to hide remittances the further away the mobile money agent is from the village.

The results for interactions with whether an agent is within or outside $1 \mathrm{~km}$ of the village are reported in columns (1) and (2) of table 4. The coefficients are similar across the two regressions, and F-tests of the equality of the coefficients across the two columns fail to reject equally at the $10 \%$ level in all cases (not reported here). I therefore determine that having an agent in near proximity to the village does not affect the effectiveness of mobile money account use for smoothing rainfall shocks.

"I also look at agents within $5 \mathrm{~km}$ and $10 \mathrm{~km}$ and find similar results to $1 \mathrm{~km}$ 
Table 4: Heterogeneous effects of the impact of rainfall shocks on consumption for mobile money users and non-users

Dependent variable: Log consumption per capita

\begin{tabular}{|c|c|c|c|c|c|c|}
\hline & $\begin{array}{c}\text { agent }<1 \mathrm{~km} \\
(1)\end{array}$ & $\begin{array}{c}\text { agent }>1 \mathrm{~km} \\
(2)\end{array}$ & $\begin{array}{l}\text { rural } \\
(3)\end{array}$ & $\begin{array}{l}\text { urban } \\
(4)\end{array}$ & $\begin{array}{c}\text { drought } \\
(5)\end{array}$ & $\begin{array}{l}\text { flood } \\
(6)\end{array}$ \\
\hline \multirow[t]{2}{*}{ Rain shock } & -0.051 & $-0.070^{* * *}$ & $-0.048^{* *}$ & $-0.111^{* * *}$ & $-0.081^{* * *}$ & -0.024 \\
\hline & $(0.076)$ & $(0.021)$ & $(0.023)$ & $(0.033)$ & $(0.024)$ & $(0.036)$ \\
\hline \multirow[t]{2}{*}{ Shock*MM use } & 0.113 & $0.106^{*}$ & $0.161^{* *}$ & $0.120^{* *}$ & $0.140^{*}$ & 0.071 \\
\hline & $(0.085)$ & $(0.060)$ & $(0.066)$ & $(0.052)$ & $(0.081)$ & $(0.051)$ \\
\hline \multirow[t]{2}{*}{ Mobile money use } & -0.005 & -0.004 & -0.017 & -0.047 & -0.011 & 0.025 \\
\hline & $(0.031)$ & $(0.031)$ & $(0.039)$ & $(0.041)$ & $(0.029)$ & $(0.028)$ \\
\hline \multirow[t]{2}{*}{ Shock*MM spillover } & 0.021 & -0.039 & -0.022 & 0.058 & -0.003 & 0.015 \\
\hline & $(0.095)$ & $(0.051)$ & $(0.056)$ & $(0.047)$ & $(0.065)$ & $(0.052)$ \\
\hline \multirow[t]{2}{*}{ MM spillover } & 0.006 & -0.024 & 0.028 & $-0.076^{* *}$ & -0.009 & -0.028 \\
\hline & $(0.031)$ & $(0.030)$ & $(0.037)$ & $(0.033)$ & $(0.026)$ & $(0.026)$ \\
\hline Observations & 9,281 & 9,281 & 6,518 & 2,763 & 9,281 & 9,281 \\
\hline Number of households & 3,807 & 3,807 & 2,632 & 1,175 & 3,807 & 3,807 \\
\hline \multirow[t]{2}{*}{ Negative shock } & -0.036 & $-0.065^{* * *}$ & $0.110^{*}$ & $-0.081^{* * *}$ & $-0.056^{* *}$ & -0.009 \\
\hline & $(0.061)$ & $(0.019)$ & $(0.062)$ & $(0.024)$ & $(0.025)$ & $(0.026)$ \\
\hline \multirow[t]{2}{*}{ (A) Shock MM user } & 0.061 & 0.036 & $0.113^{*}$ & 0.009 & 0.059 & 0.047 \\
\hline & $(0.042)$ & $(0.059)$ & $(0.062)$ & $(0.042)$ & $(0.080)$ & $(0.037)$ \\
\hline \multirow[t]{2}{*}{ (B) Shock spillover } & -0.030 & $-0.108^{* *}$ & $-0.070^{* *}$ & -0.052 & -0.085 & -0.009 \\
\hline & $(0.044)$ & $(0.047)$ & $(0.049)$ & $(0.033)$ & $(0.062)$ & $(0.041)$ \\
\hline \multirow[t]{2}{*}{ (C) Shock Non MM village } & -0.051 & $-0.069^{* * *}$ & $-0.048^{* *}$ & $-0.111^{* * *}$ & $-0.081^{* * *}$ & -0.024 \\
\hline & $(0.019)$ & $(0.021)$ & $(0.023)$ & $(0.032)$ & $(0.023)$ & $(0.036)$ \\
\hline $\mathrm{F}$ test $(\mathrm{A})=(\mathrm{C})$ & 1.75 & $3.10^{*}$ & $5.95^{* *}$ & $5.26^{* *}$ & $2.99 *$ & 1.95 \\
\hline $\mathrm{F}$ test $(\mathrm{A})=(\mathrm{B})$ & 2.20 & $3.75^{*}$ & $5.25^{* *}$ & 1.29 & 2.02 & 1.03 \\
\hline $\mathrm{F}$ test $(\mathrm{B})=(\mathrm{C})$ & 0.05 & 0.59 & 0.16 & 1.54 & 0.00 & 0.08 \\
\hline
\end{tabular}

Each column refers to a household fixed effects regression run when that condition is true. Rain shock is the 1 standard deviation rainfall shock dummy. Regressions include full set of household control variables from Table 1, errors clustered at the village level and control for village characteristics which could affect the ease of sending remittances (distance to the nearest main road, distance to nearest population centre and distance to nearest market). MM spillover refers to a household in a village where others use mobile money but who doesn't use themselves. Mobile money use is a dummy variable equal to one if that household uses mobile money. The third panel reports the overall effect of the shock at the average proportion of each group in the sample and for each group separately. F tests compare whether the shock effect is equal for the three comparison groups. Village clustered standard errors in brackets, ${ }_{2}^{* * *} \mathrm{p}<0.01$, ** $\mathrm{p}<0.05, * \mathrm{p}<0.1$ 
Next I look at whether the results vary by whether the households resides in a rural or urban area by running the results separately for urban and rural households to see if there are differential effects for these groups. Mobile money services would be expected to benefit rural households more since they have less access to other ways to send remittances such as banks or designated money transfer shops (such as Weston Union) and are less likely to have friends or relative passing by regularly who could bring remittances. They are also more reliant on agriculture and so affected by rainfall shocks more directly in terms of crop losses than households in urban areas.

Separate urban and rural results are shown in columns (3) and (4) of Table 4. From the results it can be seen that rainfall shocks have negative effects in both rural and urban areas. You benefit from using mobile money when there is a rain shock in both rural and urban areas. In both these specifications I reject equality of the shock for mobile money users and non-users in villages with no mobile money users. These results suggest that both rural and urban households benefit from mobile money, possibly because they are engaging in a reciprocal relationship to share risk across urban and rural spaces, as the remittance data suggests, and because even in urban areas some households often undertake income generating activities reliant on rainfall**. F-tests of the coefficients across columns (3) and (4) fail to reject equality at the $10 \%$ level in all cases.

To see whether too much or too little rainfall have differential effects on consumption and the ability of mobile money to smooth these impacts, I separate out the effects of droughts compared to floods. A drought is defined as the difference in rainfall from the mean being more than one standard deviation below the mean and a flood as the difference in rainfall from the mean being more than one standard deviation above the mean. This is reported in Table 4, where droughts are reported in column (5) and floods in column (6).

It can be seen that it is only droughts which have a significant negative effect of $8 \%$ of per capita consumption. Floods have no significantly different effect from zero. Mobile money use is significant at the $10 \%$ level when there is a drought and the $\mathrm{F}$ test shows that mobile money using households are protected against the effects of a drought compared to households without mobile money users in their village. However, testing for equality of the coefficients across the columns I fail to reject that the coefficients on floods and drought interactions are equal at the $10 \%$ level.

\subsection{Mechanisms}

\subsubsection{Remittances}

The proposed mechanism in this paper is that mobile money allows remittances to be sent by friends and family in other locations in response to a rainfall shock at the village level and that

\footnotetext{
** $11 \%$ of households in urban areas report the main income of the household head to come from agriculture or
} livestock compared to $89 \%$ in rural areas 
this allows consumption smoothing. However, it is possible that mobile money affects consumption smoothing in other ways. One possible alternative is that mobile money allows funds to be safely stored on a mobile phone as savings which can be run down in response to a shock. A second is that households might be considered more creditworthy if they use mobile money and are able to borrow more when an adverse event happens. I am unable to explicitly reject either of these two alternative mechanisms due to limitations of the data, but the magnitude of remittance flows in response to a rainfall shock leads me to believe this is the dominant mechanism though which mobile money accounts facilitate consumption smoothing.

In the survey data used here, over $80 \%$ of respondents said they send and receive money as the main reason for using mobile money, with an equal spilt between sending and receiving as the main reason. $20 \%$ said they had ever used mobile money for savings but only $5 \%$ said this was the main reason they use mobile money. In the third round of the survey, questions were asked on who sent remittances, by what channel, from where and what their relation was to the recipient. $40 \%$ of remittances were sent by a son or daughter, $35 \%$ were sent via mobile money and $30 \%$ came form Dar es Salaam, the capital city. This suggests a story of families sharing risk with a migrant in the city via mobile money is a plausible one.

In order to test whether remittances are driving the way that mobile money protects against adverse shocks I use the data available on remittances in the third round of the survey to run the following specification:

$$
\begin{aligned}
r_{j v}= & I_{j v}+\gamma_{a} \text { Shock }_{j v}+\mu M M_{j v} \\
& +\beta_{m} M M_{j v} \cdot \text { Shock }_{j v}+\boldsymbol{\theta} \boldsymbol{X}_{j v}+\varepsilon_{j v}
\end{aligned}
$$

where $r_{j v}$ is whether a household received any remittances, and if they did receive any remittances the amount received by a household, and the other variables are as defined previously. Log income, $I_{j v}$, is included to control for income effects. $\boldsymbol{\theta} \boldsymbol{X}_{\boldsymbol{j} \boldsymbol{v}}$ is the same vector of controls. Unfortunately, data on remittance amounts is only available for the final wave of the panel and so this specification can only be run as an OLS regression for one period. It still gives an indication though whether remittances are responding to negative shocks. If remittances are the channel through which mobile money smooths aggregate shocks then the following prediction will hold:

\section{Prediction $4 \beta_{m}>0$}

so that remittances increase for mobile money users in response to an aggregate shock.

Table 5 shows the OLS regressions of a dummy variable equal to one if any remittances were received (using any method of sending remittances) and, if any remittances were received, the amount received in Tanzanian Shillings, in wave 3. Mobile money use results in the households being $15 \%$ more likely to receive remittances, as can be seen in column (1). This shows how mobile 
money has increased the probability of receiving remittances compared to other forms of receiving remittance such as using friends and neighbours to transport money physically ${ }^{\dagger \dagger}$. A rain shock does not increase the probability of receiving remittances alone or interacted with mobile money use. Rainfall shocks are unlikely to increase the probability of receiving remittances if there is no method of sending remittances. Why the rainfall shock interacted with mobile money use does not increase the probability of receiving remittances becomes more apparent when examining column (2).

Looking at column (2), when there is a rainfall shock the value of remittances received increases but only for users of mobile money. When there is a rainfall shock, mobile money using households receive 29,600 shillings more ( $\$ 10)$, approximately $4 \%$ of the median household's per capita income in wave 3 and of a similar magnitude to the fall in per capita consumption found in Table 3 . This strongly supports the mechanism that mobile money users are able to smooth rainfall shocks since they receive more remittances, and confirms prediction 4 . The point estimates for the rain shock is negative but insignificant and for mobile money users positive and significant. This suggests that mobile money is firstly increasing the probability a household receives remittances, as seen in column (1), and, when there is a rainfall shock, increases the value of remittances received. Households using mobile money receive larger values of remittances after an aggregate shock, but are not more likely to receive remittances in the first place, because households are not selecting into mobile money use based on experiencing a shock. This result therefore further supports my use of the rainfall shock as an exogenous shock.

Overall, the results on remittances are supportive of the argument that mobile money allows the smoothing of rainfall shocks through remittance flows. However, it is still possible that mobile money accounts facilitate saving and it is through this channel that they enable consumption smoothing after a rainfall shock. The NPS data unfortunately does not include data on the value of savings in any form nor of the value of assets, meaning that I cannot directly examine saving changes by mobile-money-using and non-mobile-money-using households in response to a rainfall shock. I do however check whether household assets are declining in response to the rainfall shocks, and find no evidence of this, suggesting durable assets are not being used by households as a way to smooth consumption after the rainfall shock (results available on request).

\subsubsection{Effect of rainfall shocks}

I show that rainfall shocks have a negative effect on consumption for households without mobile money services. To examine why rainfall shocks have a negative effect on consumption I look at crop yields as the potential channel. For agricultural households, rainfall shocks would be expected

\footnotetext{
${ }^{\dagger \dagger} 35 \%$ of households send remittances via friends or family and $35 \%$ via mobile money
} 
Table 5: OLS regression of remittances received after an aggregate shock

received remittances value of remittances received

\begin{tabular}{lcc} 
Rain shock & 0.025 & $-1,589$ \\
& $(0.024)$ & $(7,010)$ \\
Rain shock*MM use & -0.019 & $29,582^{* *}$ \\
& $(0.030)$ & $(14,412)$ \\
\multirow{2}{*}{ MM use } & $0.154^{* * *}$ & $24,840^{* * *}$ \\
& $(0.020)$ & $(8,404)$ \\
\hline Control mean & 0.177 & 35,058 \\
\hline Observations & 3,240 & 3,240 \\
R-squared & 0.131 & 0.109 \\
\hline
\end{tabular}

Full set of control variables as in Table 1 and errors clustered at the village level. Log income per capita is also controlled for. All regressions also control for village characteristics which could affect the ease of sending remittances. These are the distance to the nearest main road, distance to nearest population centre and distance to nearest market. MM use is a dummy variable equal to one if the household used mobile money in a given year. The values for amount of remittances received have been winsorized at $99 \%$. Control mean refers to the mean value amongst those who don't use mobile money.

Village clustered standard errors in brackets, ${ }^{* * *} \mathrm{p}<0.01,{ }^{* *} \mathrm{p}<0.05,{ }^{*}$ $\mathrm{p}<0.1$

to reduce crop yields, particularly droughts. To test this I create a measure of crop yields using the value of crops per acre (Gollin and Udry, 2017) to account for the large variety of different crops grown in Tanzania. I regress this on the rainfall shock dummy, controlling for plot characteristics and crop dummies .

The resulting regressions of rainfall shocks on crop yields are shown in Table 6. I define the rainfall shock in 3 ways; firstly as the 1 standard deviation rainfall shock, secondly only as negative deviations (droughts) and lastly as only positive deviations (floods). Overall there is no effect of rainfall shocks on crop yields but a strong negative effect of droughts and a strong positive effect of floods. When a drought occurs crop yields fall $13 \%$ and when more rainfall occurs crop yields increase $13 \%$. This fits very much with the literature showing that crops benefit from too much 
Table 6: Effect of rainfall shocks on crop yields

Dependent variable: Log crop value per acre

\begin{tabular}{lccc}
\hline & $(1)$ & $(2)$ & $(3)$ \\
& Rainfall shock & Drought & Flood \\
& & & \\
\hline Shock & 0.031 & $-0.134^{* *}$ & $0.137^{* * *}$ \\
& $(0.043)$ & $(0.062)$ & $(0.051)$ \\
\hline Observations & 5,698 & 5,698 & 5,698 \\
Number of households & 2,646 & 2,646 & 2,646 \\
R-squared & 0.126 & 0.127 & 0.128 \\
\hline
\end{tabular}

Crop yields defined as the log of value of crops per acre.

Control variables include crop and district dummies to account for fixed characteristics of crops response to rainfall and of the value of crops in different areas. Standard errors clustered at the village level. Rainfall shock refers to a 1 standard deviation in either direction deviation from mean.

Drought is a negative deviation, flood a positive.

$* * * \mathrm{p}<0.01, * * \mathrm{p}<0.05, * \mathrm{p}<0.1$

rainfall (up to a point) but strongly decline from too little rainfall (Paxson, 1992; Suri, 2003). It also fits with my heterogeneity results in Table 4 columns (5) and (6) showing that shocks negatively affect consumption and mobile money mitigates this is entirely driven by droughts, not floods ${ }^{\ddagger \ddagger}$. These results therefore support my main conclusions.

\subsection{Robustness}

I run a number of difference tests to test the validity of my findings to selection into mobile money using being correlated with consumption smoothing ability. First I run a placebo regression using two periods of data before the introduction of mobile money to check if people who went on to use mobile money, and areas which gained agents, were already better able to smooth consumption compared to places with no users and agents before mobile money was introduced. Then I run

\footnotetext{
¥† These results are not directly comparable since the sample for crop yields only includes agricultural households whereas the main sample includes households not working in agriculture, for whom floods might have other negative repercussions on consumption and for whom droughts won't directly negatively affect. My results hold for urban as well as rural households suggesting other effects than just rainfall directly impacting crop yields are also causing rainfall to impact consumption
} 
an IV regression to further test for any potential self-selection into mobile money use. These tests cannot reject my earlier results but should be interpreted with caution due to imprecise estimates.

\subsubsection{Placebo test}

The placebo test allows me to test if future mobile money exposure predicts past changes in consumption and the ability of households to smooth shocks, thus testing if my results are consistent with the common trends assumption required for a difference-in-difference specification. The placebo test can confirm whether there is something different about households and villages which will use mobile money in the future and if this difference allows households to better smooth shocks. For example, a location is more industrialised, mobile money agents are more likely to locate in industrial areas, households are more likely to use mobile money and households working in industry are better able to smooth rain shocks. This could create a spurious correlation positive relationship between mobile money use and smoothing shocks, whereas actually the industrialisation is allowing shocks to have less impact on consumption. If this case were true then the placebo test would show a positive effect of future mobile money use for smoothing rainfall shocks in the past.

I run a placebo test using the 2007 Tanzanian Household Budget survey (HBS) combined with the NPS 2008-9 wave 1 to construct two rounds of data prior to the introduction of mobile money services. A subsample of the 2007 HBS was re-sampled in the NPS, so by combining this sample with the first wave of the NPS I created a panel of 1,200 households in 191 villages covering 2 periods before the introduction of mobile money, which I call wave 0 (2007) and wave 1 (2008-9). I created a dummy variable for whether the household ever uses mobile money after it's introduction in 2009 and whether the household is ever a spillover household (lives in a village with other users but doesn't use themselves) and I use this to estimate the following equation:

$$
\begin{aligned}
C_{j i t}= & \gamma_{a} \text { Shock }_{j v t}+\mu M M F_{j v t}+\beta_{m} M M F_{j v t} \cdot S h o c k_{j v t} \\
& +\mu M M S F_{j v t}+\beta_{m} M M S F_{j v t} \cdot S h o c k_{j v t} \\
& +\boldsymbol{\theta} \boldsymbol{X}_{j v \boldsymbol{t}}+\boldsymbol{\psi} \boldsymbol{X}_{\boldsymbol{j} \boldsymbol{t}} \cdot S_{h o c k_{j v t}}+\alpha_{j}+\varepsilon_{j v t}
\end{aligned}
$$

where $M M F_{j v t}$ is a dummy variable equal to zero in wave 0 and one in wave 1 if the household ever uses mobile money in the future and $M M S F_{j v t}$ is a dummy variable equal to one in wave 1 if the household ever lives in a village with other users but doesn't use mobile money itself in the future.

If the common trends assumption holds then the dummy for future mobile money use interacted with the shock will not be significant for the past data, confirming that it is not unobservable characteristics of households which choose to use mobile money that is driving my results. Likewise, 
the dummy for being a spillover household interacted with the shock will not be significant for the past data. A finding of no significance on these coefficients suggests that the households and villages where mobile money are used were similar in their ability to smooth shocks to the household and villages where no-one uses mobile money before the introduction of mobile money services, which is crucial for the validity of my results.

I constructed the same measures of control variables to match those used for in the main analysis such as household head education, household size, financial use and occupation dummies. The rainfall shock variable used here is a 1 standard deviation rainfall shock.

The results in Table 7 show the placebo test of future mobile money use or presence on consumption per capita ${ }^{\S}$.

I find no significantly different effect for households which use mobile money or reside in village with other users in the future on their consumption or ability to respond to a shock in the past. These are confirmed in the F statistics reported at the bottom of the table; the shock has no differential effect on households which go on to use mobile money or that become spillover households in the future. However, the rainfall shock is not leading to a significant fall in consumption in the placebo sample, and the coefficients on the shock interactions with future mobile money use are positive, and the standard errors are large, meaning I may be underpowered to detect effects. If anything though, the point estimate on the shock interacted with being a spillover household is over twice the size as the coefficient on the shock interacted with mobile money use, suggesting if anything spillover households were better able to insure shocks in the past and yet I find no positive spillover effect of mobile money.

These results are consistent with the common trends assumption needed for my use of a difference-in-difference specification to be valid. However the large standard errors suggest I cannot confirm that households which went on to use mobile money weren't already better able to smooth shocks in the past, which may create positive bias in my results.

I also test whether agents choose to locate in areas with certain characteristics. To do this I use the wave 0 data to examine whether changes in the average characteristics of households in a village or village services changes predict mobile money agent presence in a future period. The time series nature of the data therefore allows me to see whether the roll-out of agents was effectively random or could be causing spurious results by being correlated with village characteristics which facilitate risk sharing. In particular, this allows me to test if other aggregate shocks, which appear as changes in total village consumption, influence agent location choice. These results are shown in Table 8 .

\footnotetext{
$\S \S$ Note, the HBS and NPS used slightly different ways of recording consumption, principally in pricing of home produce, the number of food items, and recall versus diary methods (Tanzania National Bureau of Statistics 2009).
} 
Table 7: Placebo test of future mobile money use 2007-2008/9

Dependent variable: Log consumption per capita

\begin{tabular}{|c|c|}
\hline & $\begin{array}{l}(1) \\
\mathrm{FE}\end{array}$ \\
\hline Rain shock & $\begin{array}{l}-0.023 \\
(0.053)\end{array}$ \\
\hline Shock*MM ever & $\begin{array}{c}0.024 \\
(0.079)\end{array}$ \\
\hline MM ever & $\begin{array}{l}-0.007 \\
(0.055)\end{array}$ \\
\hline Shock*MM spillover ever & $\begin{array}{c}0.057 \\
(0.088)\end{array}$ \\
\hline MM spillover ever & $\begin{array}{l}-0.030 \\
(0.058)\end{array}$ \\
\hline Observations & 2,173 \\
\hline Number of households & 1,183 \\
\hline R-squared & 0.557 \\
\hline Negative shock & $\begin{array}{r}-0.008 \\
0.044\end{array}$ \\
\hline (A) Shock MM user & $\begin{array}{c}0.00 \\
0.073\end{array}$ \\
\hline (B) Shock spillover & $\begin{array}{l}0.034 \\
0.080\end{array}$ \\
\hline (C) Shock Non-MM village & $\begin{array}{c}-0.026 \\
0.054\end{array}$ \\
\hline $\mathrm{F}$ stat $(\mathrm{A})=(\mathrm{C})$ & 0.09 \\
\hline $\mathrm{F}$ stat $(\mathrm{A})=(\mathrm{B})$ & 0.09 \\
\hline $\mathrm{F}$ stat $(\mathrm{B})=(\mathrm{C})$ & 0.42 \\
\hline
\end{tabular}

All regression include a full set of control variable from Table 1, time dummies and clustered errors at the village level. The shock variable here is a 1 sd rainfall shock. This regression uses 2007 and 2008-9 data with a dummy variable MM ever if a household ever used mobile money after 2009. MM spillover ever refers to a household who will live in a village with at least one mobile money user in the future but never uses mobile money itself

Village clustered standard errors in brackets, ${ }^{* * *} \mathrm{p}<0.01,{ }^{*} * \mathrm{p}<0.05,{ }^{*} \mathrm{p}<0.1$ 
I find no effect of changes in any of the average characteristics of the households or the village services on either agent presence in a village or within $5 \mathrm{~km}$. Only one service is significant, with places that gained a primary school less likely to get a mobile money agent, but this could be due to chance considering the number of variables tested. Jointly, all the variables are not significant at predicting whether an agent decides to set-up in that villages, as shown by the very small $\mathrm{F}$ statistic. However, the standard errors on all the coefficients are very large, hence I should interpret this as a lack of evidence against my main results rather than support for them.

\subsubsection{IV regressions}

As discussed in the Identification Section, if mobile money use is endogenous to household's ability to smooth consumption after a shock then my results will be biased. I can use instrumental variable regression to control for this. Given there are two potentially endogenous variables, mobile money use and the shock interaction with mobile money use, I need two instruments. An instrument would need to be correlated with mobile money use (relevant) but not affect consumption smoothing independently (exogenous).

An instrument that has been used in the literature is distance to the nearest mobile money agent. Distance to the nearest agent is correlated with mobile money use since it is easier to use mobile money if an agent is nearby. And it shouldn't be correlated with unobserved determinants of the ability of households in a village to smooth risk. In addition to the distance to the nearest agent, which is only present in the case there is no agent within the village, I also have a dummy indicating whether there is a mobile money agent in the village or not. Together these two variables define access to a mobile money agent, since it is only when there is no agent in the village that the distance to the nearest agent matters. I therefore instrument with the distance to and presence of a mobile money agent and the interactions of distance to and presence of a mobile money agent with the rainfall shock.

The instrumental variable results in Table 9 confirm that the rainfall shock has a negative effect on consumption per capita of $12 \%$. None of the other coefficients are significant, though the point estimate on the mobile money shock interaction is positive and large, but with large standard errors. If anything the coefficient on the interaction of mobile money use with the shock seems of an overly large magnitude of over 2.5 times the size of the negative shock. The standard errors on all the coefficients are large, suggesting the strength of my instruments should be examined. Additionally, I am trying to instrument for two endogenous variables which also results in a loss of precision and hence high standard errors.

I report a number of different tests beneath the regression results to confirm the validity of my instruments. Firstly, the F-statistics on the first stage regressions for mobile money use and the 
Table 8: Agent location choice

(1)

Agent in village

(2)

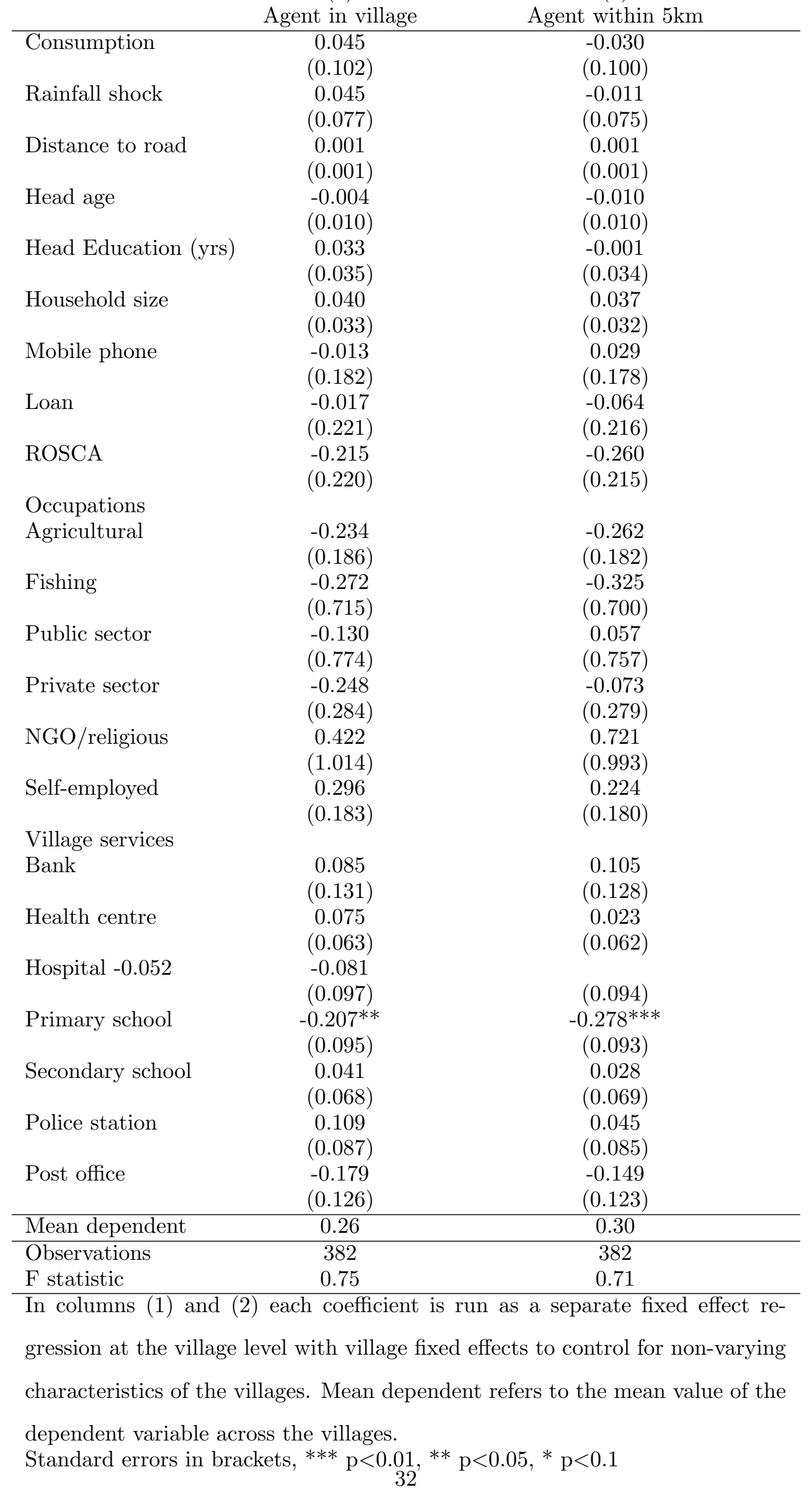


interaction with the shock are moderately large, showing that the instruments do explain variation in these variables and hence supporting their use as valid instruments. The Cragg-Donald Wald F statistic is used to test the strength of more than one excluded instruments. For the IV regressions to have less than $5 \%$ of the bias of OLS the critical value for the F-statistic is 13.43 . My CraggDonald Wald F statistic exceeds this critical value, again supporting the validity of my instruments.

The underidentification test tests the null hypothesis that the equation is underidentified. The null is rejected at the $1 \%$ level. The Sargan-Hansen test is an over-identification test which determines if the instruments are exogenous. The null hypothesis is that the instruments are uncorrelated with the error term. Since my errors are clustered, the Hansen J statistic is reported. I cannot reject the null hypothesis that all my instruments are valid.

Overall, my IV results cannot reject my main findings, but are not precise enough to definitely rule out endogeneity. 
Table 9: IV results

Dependent variable: Log consumption per capita

(1)

IV FE

\begin{tabular}{lc} 
Rain shock & $-0.120^{* *}$ \\
Rain shock*MM use & $(0.058)$ \\
& 0.297 \\
Mobile money use & $(0.198)$ \\
& -0.184 \\
Rain shock*MM spillover & $(0.295)$ \\
& 0.057 \\
MM spillover & $(0.072)$ \\
& -0.037 \\
Observations & $(0.111)$ \\
Number of households & 4,448 \\
\hline F-stat on excluded instruments for MM use & 2,224 \\
F-stat on excluded instruments for Rain shock*MM use & 19.7 \\
Cragg-Donald Wald F statistic & 27.9 \\
Underidentification test $\chi^{2}$ p-value & 25.1 \\
\hline Sargan-Hansen test $\chi^{2}$ p-value & 0.00 \\
\hline
\end{tabular}

Instruments were distance to nearest mobile money agent and a dummy indicating a mobile money agent within the village, and their interactions with the shock variable. All regressions include full set of household control variables from Table 1, household fixed effects and errors clustered at the village level. All regressions also control for village characteristics which could affect the ease of sending remittances. These are the distance to the nearest main road, distance to nearest population centre and distance to nearest market. MM spillover refers to a household in a village where others use mobile money but who doesn't use themselves. Mobile money use is a dummy variable equal to one if that household uses mobile money. Rainfall shock is the 1 standard deviation rainfall shock.

Village clustered standard errors in brackets, ${ }^{* * *} \mathrm{p}<0.01,{ }^{*} \mathrm{p}<0.05,{ }^{*} \mathrm{p}<0.1$ 


\subsection{Discussion}

Exploring why only mobile money users can smooth aggregate shocks would advance our understanding of how informal risk sharing arrangements operate in developing countries and how they are changing in an increasingly connected world. For example, are mobile money using households choosing to hide remittances (Kinnan, 2017) or are they opting out entirely from the risk sharing network in the village to share with a wider network of family anf friends (Fafchamps and Lund, 2003)? Looking at transfers within the village and from a migrant in response to shocks would allow these effects to be separated. My data was not detailed enough on specific network partners and remittance flows to answer this question, but the answer is important for understanding how new technologies change traditional risk sharing patterns and for a deeper understanding of how risk sharing networks are sustained.

There are many potential explanations for why remittances might not be shared within villages after an aggregate shock. The main one discussed here is mobile-money-using households are not participating in risk sharing networks within the village but instead insuring within wider networks of family and friends outside the village.

Mobile-money-using households have a cheap and easy way to share remittances across wide ranging geographical locations. They could insure both village-level rainfall shocks and idiosyncratic shocks through family migrants in other locations. The benefits of this risk sharing relationship would exceed those of the village risk sharing relationship as a cross-locational network allows for a lower correlation in income shocks and for the insurance of village-clustered shocks such as the rainfall shocks examined here. In this case, mobile money using households might no longer participate at all in village risk sharing.

It would be interesting future work to examine how money money is changing risk sharing relationships, potentially allowing them to cover wider geographical areas and so insure more different types of shocks. It is also important to understand under what circumstances and with who they still share risk within the village. This raises the question of if there is a shrinking pool of non-mobile-money-using households in the village without a potential migrant or too old or poor to make use of mobile money struggling to share risk with each other. While mobile money benefits users, it could increasingly penalise those unable or not willing to use it if users share less and less within the village. 


\section{Conclusion}

Household in developing countries are subject to large changes in consumption due to aggregate shocks, such as rainfall shocks, which negatively affect the consumption of the entire village at one. Droughts and floods are a major source of risk to developing households, and measures which help protect against these, ranging from social protection to micro-insurance, are key new areas of research. Mobile money services are a new and fast growing technology which can help households insure their consumption against aggregate shocks by providing access to remittances from other locations not affected by the shock.

In this paper I show that large rainfall shocks negatively affect household consumption but that mobile money use can mitigate this impact by allowing the easy sending and receiving of remittances. This effect is found regardless of whether a mobile money agent is nearby the village or not, and I cannot reject equal results regardless of whether a household is urban or rural or the shock is a drought or flood. I confirm the mechanism through which mobile money accounts enable risk sharing by looking at flows of remittances after a rainfall shock and find the value of these flows can cover the majority of a consumption drop. I also test the mechanism by which rainfall shocks lead to consumption shortfalls by examining the effect of rainfall shocks on crop yields for agricultural households, finding that droughts lead to a $13 \%$ reduction in crop yields. I confirm the robustness of my findings using a placebo test from before the introduction of mobile money to test that households which did and didn't go on to use mobile money didn't already differ in their ability to smooth risk. I also use instrumental variable techniques to address potential self-selection effects into mobile money use. Both of these are unable to reject my main results.

Mobile money only helps smooth rainfall shocks if your household uses mobile money, it is not enough for neighbours in your village to be users. This raises the question of why remittances aren't being shared with others in the village after an aggregate shock. One potential explanation discussed is that mobile money allows easy sending of remittances across networks with members in different locations, such as between family migrants to cities and the remaining family in a village, therefore decreasing reliance on traditional village risk sharing networks or networks confined to a small geographical area. This explanation would be interesting to understand in more detail and in particular to understand if this additional option for mobile money using households comes at the expense of non-mobile-money-using households in their villages who are more reliant on risk sharing with members of their village.

Research on the impact of mobile money services is still in its infancy and further work could explore in more detail how access and use of mobile money services changes traditional risk sharing arrangements and who the winners and losers are from this. 


\section{References}

Aron, J. (2017). 'Leapfrogging': a Survey of the Nature and Economic Implications of Mobile Money.

Batista, C. and Vicente, P. C. (2014). Introducing mobile money in rural mozambique: Evidence from a field experiment. NOVAFRICA Working Paper Series No. 1301.

Blumenstock, J. E., Eagle, N., and Fafchamps, M. (2016). Airtime transfers and mobile communications: Evidence in the aftermath of natural disasters. Journal of Development Economics, $120(\mathrm{C}): 157-181$.

De Weerdt, J. and Dercon, S. (2006). Risk-sharing networks and insurance against illness. Journal of Development Economics, 81(2):337-356.

Dercon, S. (2002). Income risk, coping strategies, and safety nets. The World Bank Research Observer, 17(2):141-166.

Fafchamps, M. and Lund, S. (2003). Risk-sharing networks in rural Philippines. Journal of development Economics, 71(2):261-287.

Finscope (2013). Finscope Tanzania 2013 survey. Technical report.

Gertler, P. and Gruber, J. (2002). Insuring consumption against illness. American Economic Review.

Gollin, D. and Udry, C. (2017). Heterogeneity, Measurement Error, and Misallocation: Evidence from African Agriculture.

GSMA (2010). What makes a Successful Mobile Money Implementation? Learnings from M-PESA in Kenya and Tanzania.

International financial Coporation (2010). M-Money Channel Distribution Case - Tanzania Vodacom Tanzania M-PESA.

Jack, W. and Suri, T. (2011). Mobile money: The economics of m-pesa. Nber working papers, National Bureau of Economic Research, Inc.

Jack, W. and Suri, T. (2014). Risk sharing and transactions costs: Evidence from Kenya's mobile money revolution. American Economic Review, 104(1):183-223.

Jensen, R. (2000). Agricultural volatility and investments in children. American Economic Review, pages 399-404. 
Kazianga, H. and Udry, C. (2006). Consumption smoothing? livestock, insurance and drought in rural Burkina Faso. Journal of Development Economics, 79(2):413-446.

Kinnan, C. (2017). Distinguishing barriers to insurance in Thai villages.

Mbiti, I. and Weil, D. N. (2011). Mobile banking: The impact of m-pesa in Kenya. NBER Working Papers 17129, National Bureau of Economic Research.

Munyegera, G. K. and Matsumoto, T. (2016). Mobile Money, Remittances, and Household Welfare: Panel Evidence from Rural Uganda. World Development, 79(C):127-137.

Paxson, C. H. (1992). Using weather variability to estimate the response of savings to transitory income in Thailand. The American Economic Review, pages 15-33.

Rosenzweig, M. R. (1988). Risk, implicit contracts and the family in rural areas of low-income countries. The Economic Journal, pages 1148-1170.

Shkaratan, M. (2010). Tanzania's infrastructure. World Bank Research Policy Working Series.

Suri, T. (2003). Spillovers in village consumption: Testing the extent of partial insurance. New Haven, Conn.: Yale University. mimeo.

Townsend, R. M. (1994). Risk and insurance in village India. Econometrica: Journal of the Econometric Society, pages 539-591.

Udry, C. (1994). Risk and insurance in a rural credit market: An empirical investigation in northern Nigeria. The Review of Economic Studies, 61(3):495-526.

USAID (2013). Tanzania mobile money assessment and case study.

Yang, D. and Choi, H. (2007). Are remittances insurance? evidence from rainfall shocks in the Philippines. The World Bank Economic Review, 21(2):219-248. 